\title{
Molta pressió
}

Raül Oswaldo Senra Jiménez (rauloswaldos@hotmail.com) IES Azorín (Petrer)

José María Díaz-Crespo Ramírez (placido_22@hotmail.com) Escola Científic Avel-li Corma (Moncofa, Castelló)

Al Taller de ciència amb alumnes de 5 anys a la nostra escola, el nostre objectiu principal ha estat desenvolupar habilitats de pensament científiques en els xiquets i xiquetes, mitjançant propostes $i$ experiments senzills organitzats per sessions i que té un fil conductor: la pressió atmosfèrica. Al llarg de quasi tres mesos del nostre taller, hem abordat el mètode científic contant contes, acumulant informació i materials, emetent hipòtesis, aprenent de les nostres errades, creant fenòmens sorprenents i registrant allò que hem aprés en diverses fitxes. I a més els xiquets s'ho han passat d'allò més bé i el cost econòmic és molt reduït, per la qual cosa animem a tots els docents d'aquesta etapa a que incorporen la ciència al seu horari setmanal.

Paraules clau: Educació Infantil, mètode científic, pressió atmosfèrica

In the science workshop with 5-year-old children in our school, our aim has been to develop scientific thinking abilities in them through easy experiments in different sessions. The common purpose is atmospheric pressure. In this three-month workshop we have dealt with the scientific method telling stories, accumulating information and materials, explaining hypothesis, learning from mistakes, creating amazing phenomena and noting down everything we have learnt in different worksheets. Children have plenty of fun and the cost of the workshop is really low. For this reason, we encourage all the teachers at this level to include science in their timetables.

Keywords: Childhood Education, scientific method, atmospheric pressure.

\section{PER QUÈ LA CIÈNCIA EN EDUCACIÓ INFANTIL?}

La pretensió d'aquest modest article és oferir al mestre un material més a utilitzar en la didàctica de les ciències, un àmbit que apareix prou abandonat a l'etapa de l'Educació Infantil. Es tracta de la continuació d'un altre article, publicat a aquesta mateixa revista (Suficial no, tensió su-per-fi-ci-al) per part dels mateixos autors.

Abans d'abordar la pràctica, cal entendre que el dia a dia de les nostres aules tenen tres pilars fonamentals on es desenvolupen les vivències $i$ aprenentatges del dia a dia: els hàbits i les rutines, els projectes de treball i els tallers. Mitjançant aquestos tres eixos s'organitzen i s'aborden els diferents objectius i continguts de l'etapa. En el cas dels taller, com els que ens ocupa, el seu objectiu principal és abordar aquells aspectes del currículum que no es treballen suficientment als projectes de treball i als hàbits i rutines. Nosaltres organitzem un taller de noves tecnologies i uns altres de música, anglès, filosofia, matemàtiques, contes, lletres, cuina i, com no, de ciència.

Però per a justificar el taller que ens ocupa resulta adequat abordar la necessitat de treballar les ciències a l'Educació Infantil partint dels estudis de Howard Garner i les seves intel-ligències múltiples. Partint d'aquesta base cal reflexionar que tots naixem amb una sèrie de característiques biològiques i d'una capacitat d'adaptació al medi que ens envolta per mitjà de la intel-ligència; la capacitat per desenvolupar aquesta intel-ligència depèn de l'educació i de l'ambient en el qual es trobe el xi- 
quet. Des d'aquest punt de partida, Gardner reconeix vuit intel-ligències: lingüística-verbal, físicacinestèsica, lògica-matemàtica, espacial, musical, interpersonal, intrapersonal i naturalista.

A l'escoleta massa vegades, influenciats per pressions externes o internes o pels llibres de texts que nosaltres mateixos seleccionem, ens limitem a concentrar-nos en el predomini de les intel-ligències lingüística i matemàtica, donant mínima importància a la resta de les altres possibilitats del coneixement. El taller de ciència, per exemple, resulta excel-lent per a treballar la intel-ligència naturalista - la qualitat de relacionar-se amb la natura des del coneixement i de l'afecte-; els nens que tenen aquesta intel-ligència més desenvolupada exploren i investiguen la flora, la fauna i el món físic i químic del seu voltant. Però al nostre taller també es desenvolupen $i$ es promouen altres tipus d'intel-ligència. Per exemple, la lingüística-verbal, per la gran quantitat de raonaments, hipòtesis i conclusions que cal extraure durant la sessió; també la matemàtica, perquè es treballa la resolució de problemes, l'experimentació i l'establiment de relacions entre diversos fenòmens. A més, la intel-ligència espacial s'aborda en el moment al qual els xiquets han de representar l'experiment que han realitzat prèviament i en múltiples experiències on cap treballar continguts espacials. Per suposat que la intel-ligència interpersonal i la intrapersonal són claus en totes les sessions, ja què el respecte cap a les opinions i actuacions dels companys, a les normes de seguretat o a la meditació de les pròpies accions i dels demés són una de les pedres angulars del ritme a l'aula.

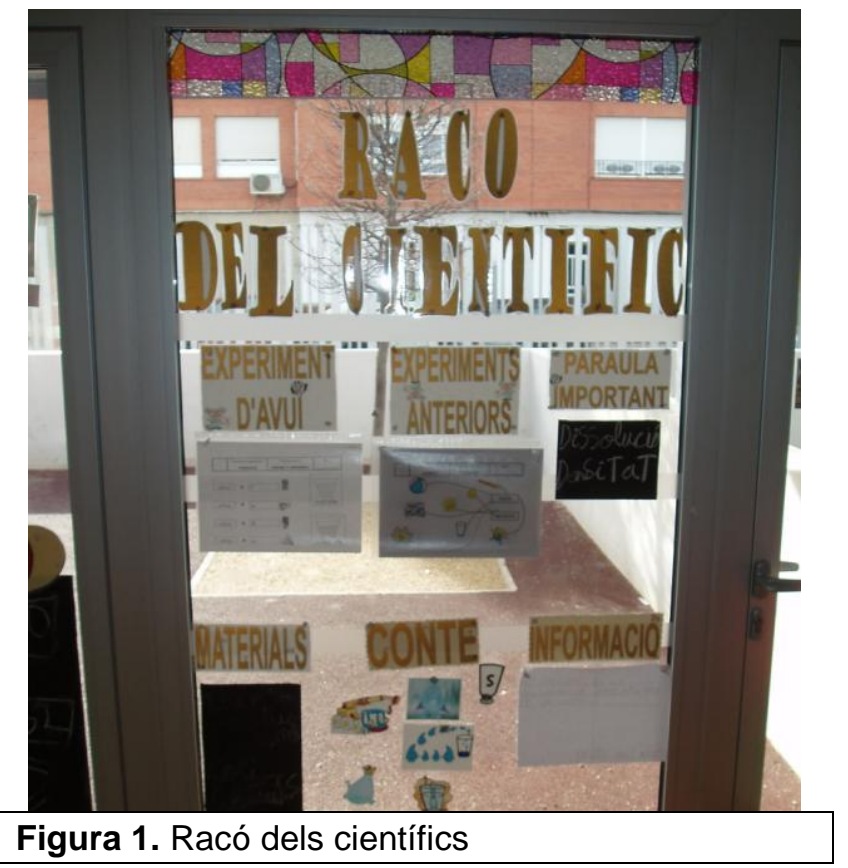

D'aquesta manera observem com d'adequat, de necessari i quasi d'imprescindible es presenta el treball de la ciència a la nostra etapa.

\section{COM FUNCIONEM?}

Motivació, activitat i reflexió. Heus ací la tècnica i el fonament del taller de ciència per a 5 anys. Només si els continguts curriculars són significatius per a l'alumne i estan vehiculats en esquemes d'activitats es pot garantir un aprenentatge estable i integra; afortunadament, la motivació per la ciència és intrínseca a les activitats o experiments que realitzem per a treballar-les. Quan saludem als xiquets que han realitzat aquest taller i que ara estan en Primària sempre em recordem com de bé s'ho han passat fent experiments. A l'anterior article nostre, es pot trobar el funcionament del taller, però és podria resumir al següent esquema (figura 2).

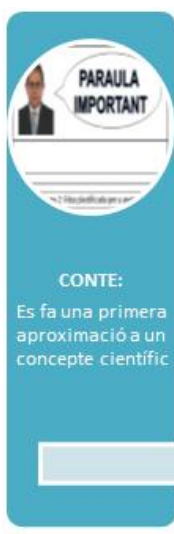

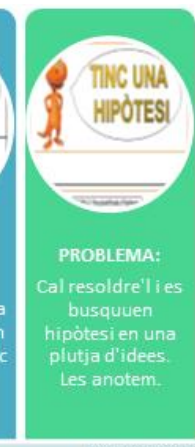
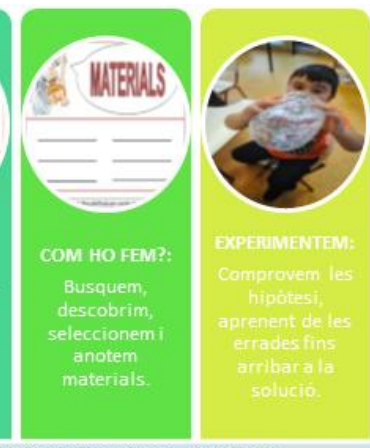

Figura 2: Com funciona el taller?

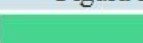

Figura 2. Com funciona el taller?
A continuació es desenvolupen els experiments que hem realitzat en diverses sessions per a treballar un concepte físic - la pressió atmosfèrica -, de forma general però abordant diversos aspectes i factors que influeixen en ella, introduint a més la pressió hidrostàtica. Cada vegada que abordem un bloc el presentem un conte que serveix per a explicar un dels conceptes 0 un experiment on s'anomena per primera vegada el concepte. Una vegada finalitza el conte, fa falta comprovar si allò que els hem contat és veritat o mentida; per a ferho passem a realitzar-ho, però abans fa falta recordar i anotar la paraula important, emetre diverses hipòtesis al voltant de l'experiment i anotar-les i enumerar i buscar els materials que ens faran falta per a realitzar l'experiment.

Una vegada que realitzem l'experiment, que normalment organitzem en quatre equips (per taules), arrepleguem i netegem i tornem al racó de ci- 
ència, on realitzarem una fitxa senzilla però on apareix o queda reflectit el procediment i/o el resultat de l'experiment.

En successives setmanes, fem nous experiments per a afegir noves variants al concepte, inicial i molt general, que els xiquets aprenen de la pressió atmosfèrica, per exemple. D'aquesta manera introduïm el mètode científic perquè es plantegen de forma resumida però constants les seves fases: observació de fets, descobriments de problemes, emissió d'hipòtesi, trobada d'informació, documents i materials, verificació experimental de l'experiència, pràctica de l'assaig i errada, extracció de conclusions, comunicació d'aquestes, discussió col-lectiva i generalització.

Cal recalcar que els experiments els han realitzat els xiquets i no el mestre, exceptuant aquelles parts que resulten un poquet més perilloses o que necessiten més supervisió. És el nen qui ha de descobrir allò que li hem plantejat amb pistes o materials, per tal que es trenquen els seus coneixements previs al respecte i es genere un nou coneixement o procediment fruit del descobriment, del raonament personal i de les seves pròpies errades. És molt important també respectar les hipòtesis de tots els demés, a pesar que no siguen correctes. En moltes ocasions vos trobareu que l'assemblea, és a dir, el gran grup, és el lloc idoni per tal d'arribar a les conclusions que nosaltres busquem, ja que les ocurrències de cadascú es complementen o s'enfronten dialècticament a les dels altres companys. Per tant, podem concloure que experimentar va unit a respectar els processos vitals de cadascú, a escoltar, a intentar comprendre, a oferir oportunitats i no a restringir-les.

\section{QUINS OBJECTIUS TENIM I COM ENS AVALUEM?}

Per als tres cursos que es porta aplicant i perfeccionant aquest taller a les nostres aules podem concloure que els següents objectius són adequats i apareixen reflectits a la nostra programació d'aula.

\begin{tabular}{|l|l|}
\hline \multicolumn{2}{|l|}{ TALLER DE CIĖNCIA 5 ANYS C.E.I.P. CIENTÍFIC AVEL-LÍ CORMA } \\
\hline $\begin{array}{l}\text { Experiment I } \\
\text { Activitat }\end{array}$ & Objectius \\
\hline Cartolina màgica & $\begin{array}{l}\text { Aproximar-se al concepte de pressió atmosfè- } \\
\text { rica com a força de l'aire }\end{array}$ \\
\hline La botella xafada & $\begin{array}{l}\text { Observar l'efecte que produeixen els canvis } \\
\text { de pressió atmosfèrica en un recipient. }\end{array}$ \\
\hline $\begin{array}{l}\text { El globus a la bote- } \\
\text { lla }\end{array}$ & $\begin{array}{l}\text { Comprovar la força de la pressió atmosfèrica i } \\
\text { com podem fer que aquesta siga inferior per } \\
\text { tal de poder unflar un globus. }\end{array}$ \\
\hline
\end{tabular}

\begin{tabular}{|l|l|}
\hline L'ou a la botella & $\begin{array}{l}\text { Observar com podem disminuir la pressió at- } \\
\text { mosfèrica esgotant l'oxigen. }\end{array}$ \\
\hline \multirow{2}{*}{ L'aigua que puja } & $\begin{array}{l}\text { Observar la disminució de pressió que es } \\
\text { produeix per la combustió de l'aire. }\end{array}$ \\
\hline \multirow{2}{*}{$\begin{array}{l}\text { La bola que no es } \\
\text { mulla }\end{array}$} & \begin{tabular}{l} 
Comprovar que l'aire ocupa volum. \\
\cline { 2 - 2 }
\end{tabular} \\
$\begin{array}{l}\text { Conèixer un altre concepte físic: la pressió hi- } \\
\text { drostàtica. }\end{array}$ \\
\hline
\end{tabular}

OBJECTIUS COMUNS A TOTES LES ACTIVITATS, SESSIONS I BLOCS DE CONTINGUT

Gaudir realitzant els experiments.

Emetre hipòtesi.

Respectar les hipòtesi dels altres.

Escoltar amb atenció el conte

Comprendre i recordar el conte.

Comprovar les hipòtesi realitzant l'experiment.

Reconèixer amb normalitat les seves pròpies errades i les dels companys.

Aproximar-se als conceptes treballats.

Arreplegar i netejar la classe.

\section{COM ENS AVALUEM?}

Mitjançant l'observació directa i sistemàtica, al nostre quadern apareixen els següents ítems on es va avaluant el progrés de l'alumne (aconseguit, en procés o iniciat):

\begin{tabular}{|l|l|l|l|}
\hline $\begin{array}{l}\text { CRITERIS D'AVALUACIÓ DEL TALLER DE } \\
\text { CIENTÍFICS }\end{array}$ & AC & EP & I \\
\hline $\begin{array}{l}\text { Coneix les paraules pressió atmosfèrica i } \\
\text { gravetat? }\end{array}$ & & & \\
\hline Gaudeix realitzant els experiments? & & & \\
\hline Es capaç d'emetre hipòtesis? & & & \\
\hline Respecta les hipòtesis dels altres? & & & \\
\hline Escolta amb atenció el conte i l'entén? & & & \\
\hline $\begin{array}{l}\text { Comprova les seues hipòtesis realitzant } \\
\text { l'experiment i reconeix amb normalitat les } \\
\text { seues errades? }\end{array}$ & & & \\
\hline S'ha aproximat als conceptes treballats? & & & \\
\hline $\begin{array}{l}\text { Ajuda a l'hora d'arreplegar i de netejar la } \\
\text { classe? }\end{array}$ & & & \\
\hline
\end{tabular}

\section{LA PRESSIÓ ATMOSFÈRICA.}

Es tracta de la força per unitat de superfície exercida per l'aire sobre la superfície terrestre. No resulta fàcil, degut a diversos factors, calcular exactament la pressió atmosfèrica sobre un lloc i nosaltres no pretenem això de cap manera. Ens marquem com a objectiu principal que els xiquets entenguen la força que exerceix aquesta pressió sobre nosaltres i sobre diversos objectes, comprovant els seus efectes amb experiments senzills, on els 
plantegem reptes o enigmes en la solució dels quals intervé aquesta força. All llarg de les diverses setmanes, la idea principal a transmetre és que la pressió atmosfèrica és la força de l'aire; el primer obstacle a superar serà la diferenciació entre aire $\mathrm{i}$ vent. Quan al principi els plantegem als alumnes si hi ha aire en eixe moment en l'aula, tots responen que no, ja què ho associen amb el vent; es trenca fàcilment aquest concepte previ preguntant $i$ què estem respirant ara mateixa? Pot ser el més sabut conteste oxigen, però de segur que sabrem reconduir la resposta cap a on nosaltres volem.

Per a entendre el primer experiment i fer una primera aproximació a la pressió atmosfèrica, cal que contem prèviament el següent conte.

Fa molt, molt de temps, n'hi havia un xiquet que, un dia, va despertar al mig d'un camp molt verd i amb moltíssimes flors. El xiquet era rosi, primet i duia un pantaló fet amb fil d'or i una camisa tota de plata fina. Quan es va alçar del terra, va mirar a un costat $i$ un altre i va descobrir que estava a soles. Aleshores es va donar compte que no sabia qui era; no es recordava dels seus pares, ni dels seus amics, ni d'on estava la casa. Com era valent, no va plorar, i va començar a córrer i a buscar gent què li digueren qui era.Caminant, caminant, va arribar a una petita granja i allà va veure un home donant de menjar a les gallines:

Perdone, senyor, m'he despertat al camp i no em recorde de res. Vostè ho sap?

Tu eres el príncep del cel - li va dir en veu baixeta -, però no et puc dir més, perquè el teu germà ens ho ha prohibit i, si no, s'enfadarà amb mi.

Després de donar-li les gràcies al granger va veure un xiquet jugant a la pilota i li va preguntar.

Perdona, sóc el príncep del cel però no em recorde d'on està el meu castell. Em pots ajudar?

El teu castell està allà dalt, en el cel. Puja a la muntanya més alta $i$ el veuràs, però no et puc dir més, perquè el teu germà ens ho ha prohibit $i$, si no, s'enfadarà amb mi.

El príncep va buscar la muntanya més alta que n'hi havia per allà i, després de molt de pujar, va arribar al cim i veure un castell de marbre blanc dalt d'un núvol; però encara estava molt lluny i de cap de les maneres podria arribar. Aleshores es va recordar que tenia fam, que tenia fred i que trobava a faltar a sa mare. Va començar a plorar. Tant, tant va plorar que sa mare, la reina del cel, el va sentir i va baixar, el va abraçar i se'l va en dur volant al castell del cel on estava el seu pare, el rei del cel.
Ai, fill meu, on estaves? Què t'ha passat?

No ho sé papà, només sé que el meu germà li ha dit a tot el món que no em deixaren tornar. Crec que em vaig caure del castell i em vaig pegar un colp al cap.

Ai fill, quina desgràcia de germà que tens! És que no et recordes de qui és? És l'AIRE - va dir son pare enfadat.

\section{I no el vas a castigar?}

No puc fill meu, perquè no sé on està. L'aire no es pot veure, no es pot tocar i no el puc agafar perquè se m'escapa de les mans.

Però aleshores, la reina va recordar:

$A i$, ja sé com el podem enxampar! Agafa un got amb aigua, tapa-ho $i$, quan digues la paraula màgica, un tros del teu germà es quedarà a dins tancat.

I no es caurà l'aigua del got?

No fill meu, perquè has de dir la paraula màgica: PRESSIÓ ATMOSFĖRICA.

I què es la pressió atmosfèrica?

És la força del teu germà l'aire, però m'has de prometre que si trobes al teu germà, el perdonaràs?

Sí mamà.

El príncep va ficar un tros de cartolina damunt $i$, quan va girar el got dient les paraules màgiques... pres-si-ó atmos-fè-ri-ca, com va dir sa mare, l'aigua no va caure. Aleshores va escolar a dins del got.

$A i$, ai, ai. Sóc el teu germà l'aire. Perquè m'has tancat al got?

Perquè em vas tirar del castell i no volies que tornara?

$A i$, per favor, perdona'm. Et promet que no ho tornaré a fer. I per a què veges que no dic mentides, et deixaré jugar amb la pressió atmosfèrica tot el que vulgues.

I, així, el príncep del cel, va tornar al seu palau, amb son pare i sa mare i el seu germà l'AIRE no el va molestar mai més.

I conte contat, ja s'ha acabat i per la finestra s'ha.... volat.

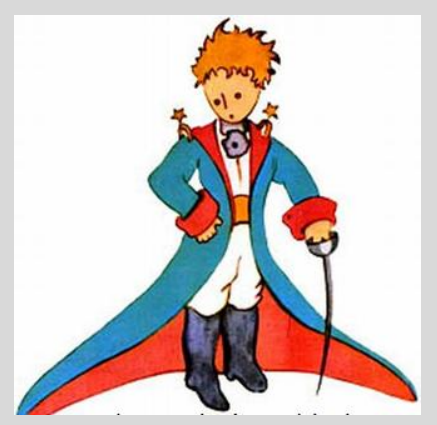

Figura 3. El príncep del cel. 


\section{EXPERIMENT 1: CARTOLINA MÀGICA.}

Objectius: Aproximar-se al concepte de pressió atmosfèrica com a força de l'aire.

Materials: Got, tros de cartolina (un poquet més gran que el diàmetre del got), aigua, safata.

Plantejament previ: Anem a comprovar si allò que us he contat al conte pot passar o no, és a dir, si amb un tros de cartolina només podem aguantar tota l'aigua que hi ha a dins del got sense que caigui quan li donem la volta.

Procediment: Col-loquem aigua fins a omplir la meitat del got. Posem el tros de cartolina damunt $i$ a continuació li donem la volta ràpidament damunt de la safata, pressionant un poquet amb la palma de la mà durant uns pocs segons i llevant la mà de forma lenta. Veuràs com la cartolina és capaç de sostenir l'aigua flotant dins del got.

Explicació: Cal recordar que la pressió atmosfèrica és la pressió que exerceix l'aire en qualsevol punt de l'atmosfera; del mateix mode l'aire exerceix pressió contra tot allò que l'envolta. En aquest experiment la pressió de l'aire ha contrarestat la força de la gravetat i ha exercit pressió damunt la cartolina; per això l'aigua pareix flotar. Resumint, l'aire espenta la cartolina cap amunt amb la suficient força com per a mantenir l'aigua dins del got uns segons o fins i tot, un o dos minuts.

Fitxa: Escriure el nom i la data. Llegir els passos que hem seguit i col-locar el número corresponent als dibuixos del procés de l'experiment per tal d'ordenar-ho correctament.

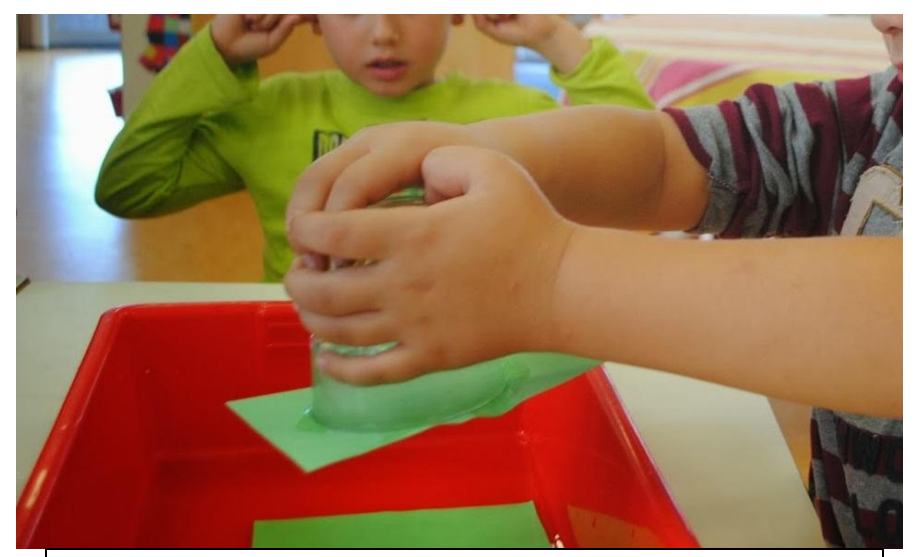

Figura 4. Cartolina màgica.

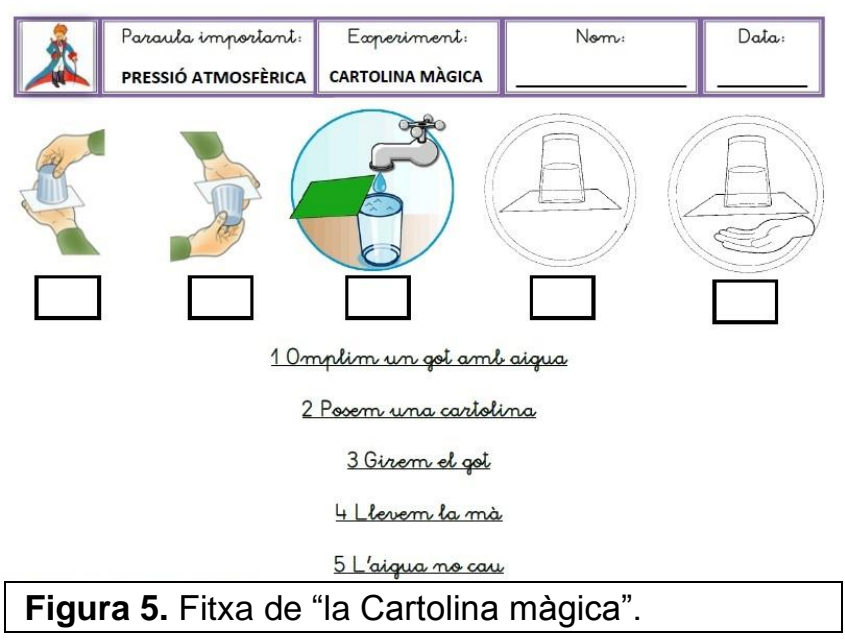

\section{EXPERIMENT 2: LA BOTELLA APLAS- TADA.}

Objectius: Observar l'efecte que produeixen els canvis de pressió atmosfèrica en un recipient.

Materials: Botelles de plàstic d'aigua buides de diverses grandàries.

Plantejament previ: L'aire es pot veure? Es pot agafar? Aleshores, la força de l'aire la podeu veure? La podeu agafar? Ni ha manera de veure-la, però per a poder fer-ho digueu-me (ensenyant una botella d'aigua buida), hi ha aire dins de la botella? $\mathrm{Hi}$ ha aire fora de la botella? Sí, perquè en eixe cas, no podríem respirar, però el que passa és que no el notem; doncs, per a poder veure la pressió atmosfèrica, la força de l'aire qui hi ha fora de la botella, necessitem traure l'aire de dins per a què faça força. Com podem fer-ho? Després de moltes discussions, al final s'ha d'arribar a la mateixa conclusió: fa falta succionar l'aire amb la boca.

\section{Procediment:}

$1^{\text {a }}$ part. Cal succionar l'aire que hi ha dins de la botella per tal que aquesta es xafi. Una vegada ho hem descobert, cal tornar a posar la botella com estava inicialment. Per a fer-ho, és necessari bufar a dins amb força. Podem provar amb botelles de diferents grandàries $i$ formes $i$ continuar fent-ho uns quants minuts perquè els xiquets s'ho passen d'allò més bé.

$2^{\text {a }}$ part. Els donem una altra botella amb tap i els diem que, utilitzant les mans, han de xafar la botella. No podran i haurem d'arribar a la conclusió que cal fer un forat a la botella (amb un punxó, per exemple) per a què puguem xafar-la. 


\section{Explicació:}

$1^{\underline{a}}$ part. Quan la botella es troba oberta, dins n`hi ha aire, que exerceix una pressió igual a la de laire que es troba al voltant de dita botella; però quan aconseguim llevar l'aire de dins, aquesta pressió és menor a la de l'aire que envolta exteriorment a la botella; per tant podem veure un canvi en la forma de la botella, ocasionada per la diferència de pressió.

$2^{a}$ part. Ara tenim una botella tancada que conté dins aire que exerceix la mateixa pressió que l’aire que envolta exteriorment a la botella. Per poder xafar la botella cal originar una diferència de pressió i és per això que, si no llevem el tap, cal fer un forat a la botella aconseguint una pressió menor dins de la botella per l'eixida d'aire; d'aquesta manera serà molt fàcil poder xafar-la.

Fitxa: Escriure nom i data. Descriure breument allò que ha succeït als dos experiments.

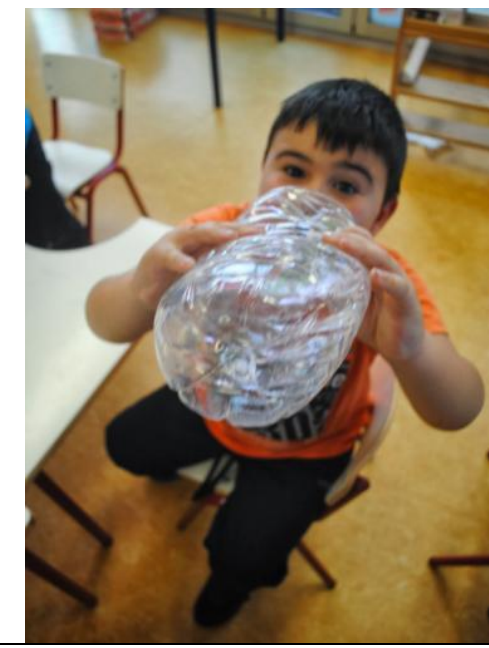

Figura 6. La botella xafada.

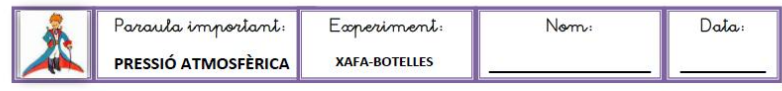

1. Que hem fet amb la botella quan hem sauclat? yis 5
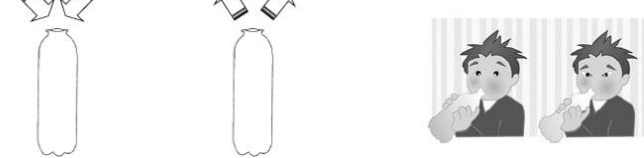

2. Que fem per a que es quede aplastada?

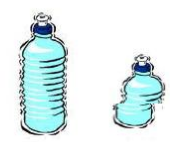

Figura 7. Fitxa de "La botella xafada".

\section{EXPERIMENT 3: EL GLOBUS A LA BO- TELLA.}

Objectius: Comprovar la força de la pressió atmosfèrica i com podem fer que aquesta siga inferior per tal de poder unflar un globus.

Materials: Globus normals, botelles d'aigua de plàstic buides, punxons o agulles.

Plantejament previ: Vos recordeu de l'experiment anterior? Hi ha aire a dins i a fora de la botella? Per què es xafava la botella quan succionàvem l'aire de dins? Doncs tenint en compte tot açò vos plantegi un repte: cal unflar un globus a dins de la botella.

\section{Procediment:}

1- part: Es col-loca el globus a la boca de la botella, cap a dins, de forma que coincideixi la boca dels globus amb la de la botella, per on bufarem per a unflar el globus. Però no podrem, per molt aire que bufem. Haurem de deduir que necessitem fer un forat al globus.

$2^{a}$ part: A més, una vegada unflat el globus, quan col-loquem el dit al forat (si l'hem fet xicotet) $i$ deixem de bufar, es mantindrà el globus unflat.

\section{Explicació:}

1aㅡ: Quan bufem amb la intenció d'unflar el globus abans d'haver fet el forat, la pressió de l'aire que està atrapat a dins de la botella no ens deixa fer-ho. Però si fem el forat xicotet a la base de la botella, l'aire ix a l'exterior i aquesta corrent lliure que produeix ens permet unflar el globus amb facilitat.

Fitxa: El mateix principi serveix per a la segona part de l'experiment, ja què, una vegada unflat, si posem el dit al forat, la pressió de l'aire de dins augmenta, per la qual cosa no permet que es desinfle el globus.

A més: si busqueu a Youtube $\odot$, trobareu molts vídeos d'aquest experiment. 


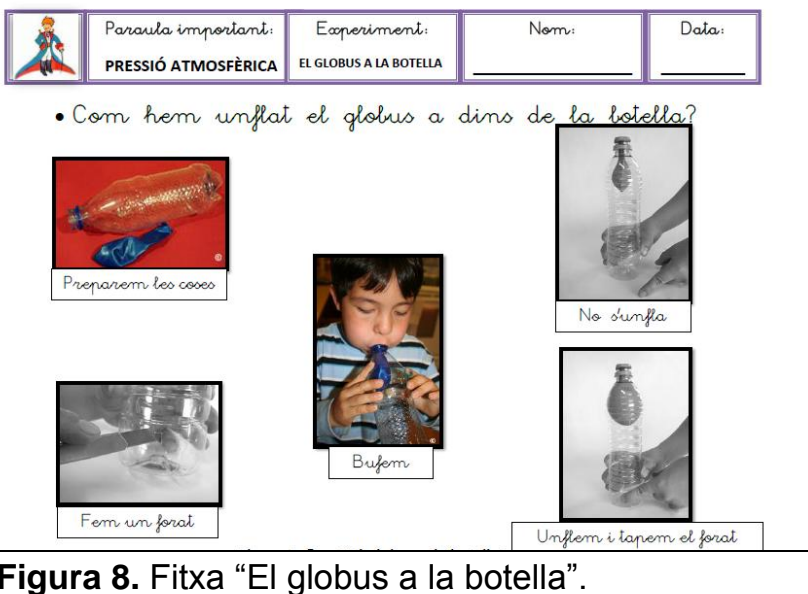

\section{EXPERIMENT 4: L'OU S'APRIMA.}

Objectius: Observar com podem disminuir la pressió atmosfèrica esgotant l'oxigen.

Materials: Botella de cristall o vidre de boca ampla - com a mínim la meitat del diàmetre de l'ou -, tires de paper, un encenedor o mistos, ous cuits $\mathrm{i}$ un poquet d'oli.

Plantejament previ: Avui hem de ficar aquest ou cuit sense trencar-ho en aquesta botella de vidre, com podem fer-ho? Els xiquets intentaran prémerho, però l'ou no entrarà o es destrossarà. Aleshores els recordarem els experiments anteriors, i com, si disminuïm la pressió de l'aire de dins de la botella, la pressió de l'aire de fora augmenta i pot empènyer l'ou. Això sí, els haurem de donar la pista de què necessitem provocar un xicotet foc a dins de la botella. Aquest experiment no podem fer-ho a soles, i el mestre ha de fer la fart més perillosa.

Procediment: Untem amb el dit un poc d'oli al voltant del coll de la botella - per tal que escorri millor -. Després encenem una de les tires de paper, l'introduïm a la botella $\mathrm{i}$ tot seguit col-loquem l'ou damunt del coll de la botella. Veuràs com l'ou s'introdueix ràpidament dins de la botella.

¿Quan col-loquem l'ou damunt de la botella amb la tira de foc encesa, la flama s'apaga perquè es consumeix l'oxigen, la qual cosa crea un buit parcial, fent que la pressió de dins disminueixi i que la pressió de l'aire de fora empenyi l'ou cap dins suaument.

Fitxa: Escriure el nom i la data. A la part superior, escriure el nom dels materials que hem utilitzat; a la part inferior de la fitxa, dibuixar els materials que hem necessitat.

A més: teniu dos vídeos amb l'experiència al nostre bloc d'aula.

http://classedelsgalls.blogspot.com.es/2014/01/p ressio-atmosferica-vs-gravetat.html

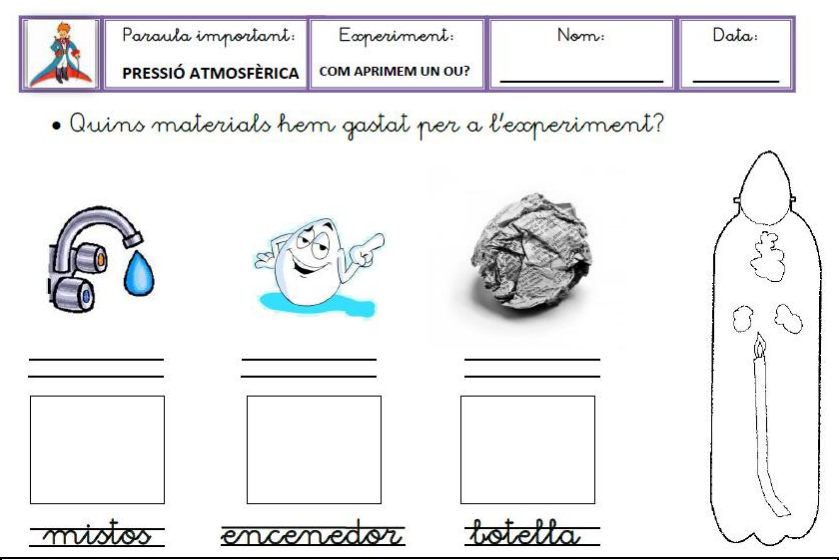

Figura 9. Fitxa "Com aprimem un ou?".

\section{EXPERIMENT 5: L'AIGUA QUE PUJA.}

Objectius: Observar la disminució de pressió que es produeix per la combustió de l'aire.

Materials: 1 ciri, 1 got transparent de tub, 3 monedes (la seva grandària dependrà de l'amplària del got), 1 plat amb aigua, colorant alimentari.

Plantejament previ: Algú es recorda de l'experiment de la setmana passada? Per què va entrar l'ou a soles a dins de la botella? Doncs, una vegada que vos heu recordat del que va passar, vos vaig a ensenyar uns materials i vos planteja un repte. Amb tot açò heu de fer que l'aigua, a soles, sense tocar-la ni bufar, es fique a dins del got que està cap a baix.

Procediment: El primer pas és posar tres monedes en un plat amb aigua i colorant i col-locar-les en forma de triangle (l'aigua ha de passar molt poc el nivell de les monedes). Entre les tres monedes cal col-locar damunt el ciri - cal calcular que el got, al girar-ho i posar-ho amb la boca cap a baix quedi damunt de les tres monedes, tocant l'aigua, sense tocar el plat i amb el ciri al mig -. Si ho heu aconseguit el següent pas és encendre el ciri i gaudir amb l'efecte: l'aigua pujarà a soles fins a la meitat del got aproximadament amb el ciri inclòs quan s'apague la flama. Màgia? No! Ciència! 
Explicació: Amb el ciri encès la flama va consumint '`oxigen que $n$ 'hi ha dins fins a que aquest s'esgota, que és quan el ciri s'apaga. Aquest fet el que origina és que es produisca un xicotet buit que fa que puje l'aigua per dins i així aconsegueix compensar aquesta diferència de pressió.

Fitxa: Escriure el nom i la data. Dibuixar i pintar l'aigua i el procés seguit a l'experiment i explicar-lo breument a les línies inferiors.

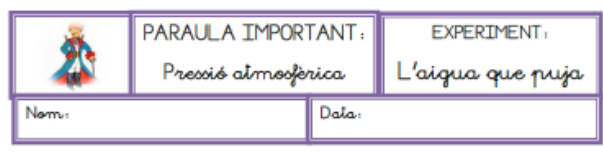

Diluisa i escriu que ha passat a l'esperiment?

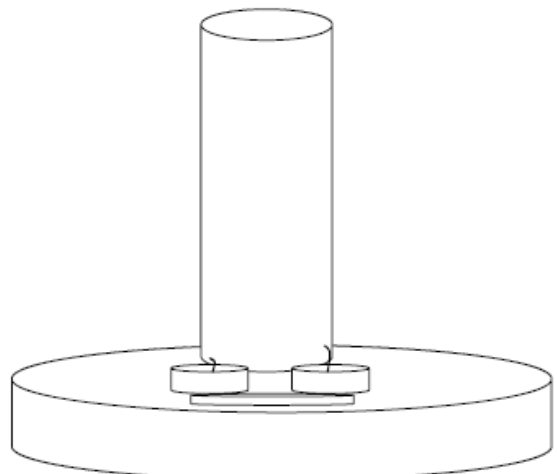

Figura 10: fitxa "L'aigua que puja"

Figura 10. Fitxa "L'aigua que puja".

\section{EXPERIMENT 6: LA BOLA QUE NO ES MULLA.}

Objectius: Comprovar que l'aire ocupa volum. Conèixer l'existència d'un altre concepte físic: la pressió hidrostàtica.

Materials: mocador de paper, cinta adhesiva, safa, aigua i got de plàstic dur o de vidre resistent.

Plantejament previ: Vos recordeu què era la pressió atmosfèrica? I què penseu que serà la pressió hidrostàtica? Molt bé! La força o la pressió de l'aigua. Doncs avui anem a fer un experiment on la pressió atmosfèrica i la pressió hidrostàtica van a xocar i a veure quina de les dos és més forta; a més, veureu amb els vostres ulls l'espai que ocupa un poc d'aire. Per a comprovar-ho vos planteja un repte; amb aquests materials, com podem omplir el got d'aigua i que no es mulle el mocador que he pegat a la base del got? És important que els xiquets agarren el got, el manipulen i intenten ficar-li aigua a dins intentant trobar la solució; de segur que algú ho aconseguirà.

Procediment: Enganxem un mocador de paper (del tipus tissues) amb cinta adhesiva al fons del got i posem el got cap per avall dins d'una safata amb aigua fins a la meitat de la seva capacitat. Després de ficar-lo a la safata de forma perpendicular dins de l'aigua i sense soltar-lo, l'hem de treure i comprovar com... El mocador està totalment eixut! Pot ser que algun xiquet no ho mantingui de forma perpendicular i que, per tant, se li rellisqui; aleshores el got s'omplirà tot d'aigua però no patiu perquè és una oportunitat magnífica per a analitzar perquè d'aquesta manera el mocador s'ha mullat.

Explicació: La pressió de l'aigua de la safa produeix una força que és sempre perpendicular a qualsevol superfície en el seu interior. Al got, l'aigua pressiona contra l'aire que conté i intenta comprimir-ho, però com que l'aire no és totalment compressible, arriba un moment en què no es pot comprimir més i ja no puja l'aigua dins del got. Per això el mocador queda eixut. L'explicació als xiquets cal simplificar-la; l'aigua, mitjançant la seva força o pressió, vol entrar dins de tot el got, però com que l'aire ocupa lloc i també té força no li deixa a l'aigua entrar del tot. Quina força ha guanyat?

Fitxa: Escriure el nom i la data. Fixar-se en els dibuixos que expliquen el procediment de l'experiment $\mathrm{i}$ escriure les paraules que falten en cada frase.

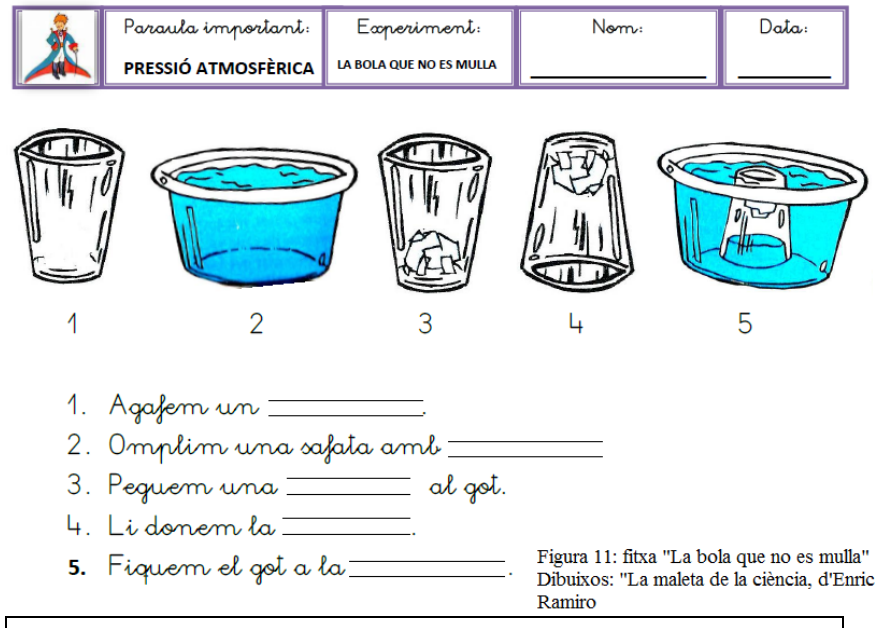

Figura 11. Fitxa "La bola que no es mulla". 


\section{SEQÜĖNCIACIÓ DEL TALLER}

Per a finalitzar, cal recalcar que el present article només mostra part de l'experiència del taller, que té una durada de tres cursos i que ocupa tot el segon cicle de l'Educació Infantil. Al nostre anterior article teniu un altre bloc de continguts, el referit a la tensió superficial $i$ en el futur apareixeran d'altres. Ací teniu la seqüència de blocs de continguts.

\section{Taller de ciència a Educació Infantil}

- Dissolució

- Densitat

- Capil-laritat

4 anys

- Tensió superficial

- Pressió atmosfèrica.

Gravetat

- Electrostàtica.

- Magnetisme.

5 anys

- Química

José María Díaz-Crespo Ramírez / Raül Oswaldo Senra Jiménez

Figura 12: seqüenciació del taller de ciència

\section{BIBLIOGRAFIA}

PERKINS, Bethany; EDWARDS, Hermione; MUGFORD, Simon (2011): Experimenta - Ciencia: experimentos sencillos para niños. La galera: Madrid.

FERNÁNDEZ PANADERO, Javier (2012): Experimentos para entender el mundo. Pàginas de espuma: Madrid.

TATARSKY, Daniel (2013): Locos por la ciencia: 50 trucos para niños de todas las edades. Grijalbo. Madrid.

AA. VV (2009): Los experimentos de Flipy, el científico loco. Aguilar. Madrid.

RAMIRO ROCA, Enric (2010): La maleta de la ciència. Graó: Barcelona.

MERCÈ IZQUIERDO (coord) GRUPO DE TRABAJO KIMEIA (2012): Química en Infantil y Primaria. Graó: Barcelona.

DÍAZ-CRESPO RAMÍREZ, José María; SENRA JIMÉNEZ, Raúl Oswaldo (2013): Suficial no, tensió su-per-fi-ci-al. Revista Ciències 26, 2-9. 